PESHAWAR JOURNAL OF PSYCHOLOGY AND BEHAVIORAL SCIENCES, 2017, VOL. 3, NO. 1, 81-93

\title{
Sex Differences in Displaying Level of Empathy in Pakistani Adults
}

\author{
Nazia Iqbal ${ }^{1}$, Naila Aslam ${ }^{2}$ \\ International Islamic University Islamabad \\ and \\ Uzma Masroor ${ }^{3}$ \\ Bahria University, Islamabad
}

Empathy is a distinctive capacity of the human being in which a person feels every aspect of others as his/her own. The objective of the research is to find out empathy in the adults of Pakistan. Is its level increasing or decreasing with time and to explore that whether this type of human emotion is much prevalent in males or in females. . Research shows that prosocial behavior and role taking has positive relation with empathy. Total one hundred and fifty $(\mathrm{N}=150)$ individuals with age ranged from 19-40 participated in this research study. About 96 were females and 54 were males. This sample was collected from Rawalpindi and Islamabad. A scale is used to measure empathy level in adults. Results indicate that there are no significant differences in adults of different age groups. It was found that females scored higher on empathy scale as compared to males. Implications of the research findings for future research on Pakistani adolescents are discussed.

Keywords: empathy ,empathy level, distinctive capacity employees, telecommunication sector.

Empathy is something that makes a person realizes and understands someone's problem as his/her own problem in the same way. Empathy is an essential building block within all relationships

\footnotetext{
${ }^{1}$ Assistant Professor, Department of Psychology, International Islamic University Islamabad, Pakistan

${ }^{2}$ MS Scholar, Department of Psychology, International Islamic University Islamabad, Pakistan

${ }^{3}$ Assistant Professor, Department of Psychology, Bahria University Islamabad, Pakistan
} 
which means to emotionally put one self in the place of another and is directly dependent on the ability to feel individual feelings and identify them. Whereas a lack of empathy means not understanding the feelings and emotions of a person by whom the individual is in a relationship. Such behavior is to blame up for relationship break ups (Pedersen \& Fenton, 2007). In perspective of psychological ground, empathy is a fundamental element of building the relationship with the client. It may help to increase satisfaction with the consultation, reduce complaints and even have better health outcomes for the patient. Empathy is an imperative capability which all people must develop to progressively leading life. It is on the whole very important in creating effective and constructive relations (Halpern, 2007). Empathy is a distinctive capacity of the human being in which a person feels every aspect of others as his/her own.

There are many variables that are relating to empathy. Some of these are role taking behavior, fantasy of imaginative thinking and prosocial behavior. The role taking is an important factor in the empathy. It can be defined as a mental understanding of opinion of another individual. Role taking is a requirement to empathy. The fantasy or imagination is also an important factor for the empathy. The fantasy can be defined as mental apprehension of an object of perception; the ability by which this is performed. The empathy has direct response of another experience. The transfer of imagination of a person to another situation may enhance empathy. The fantasy items like books, movies etc, might effect in empathy. Another significant variable related to the empathetic concern is the pro-social behavior that is related to the feelings, welfare and rights of people. It is a way of concerning for others and to be helpful for others. Empathy may contribute in pro-social behaviors as empathic understanding is helpful in reducing and minimizing hostile and antisocial behaviors. Research shows that pro-social behavior has positive relation with empathy. The role taking is positively concerned with empathy. The fantasy thoughts and role taking are playing role in enhancing the emotion of empathy (Ickes, 2003).

Being empathic depend on individual manner of social communication for that recent findings have shown link between empathy and social media usage among adolescents. Some findings have indicated that the social media have caused adolescents to be less empathetic. But however, other empirical researchers have found that social media work as source for developing empathy and social 
development in adolescents. But the social media help to improve the ability to understand (cognitive) and feelings for empathy (affective empathy) among adolescents (Konrath, O’Brien, \& Hsing, 2011). Similarly as adolescents spend more time on internet thus unable to really participate in emphatic activities (Konrath, 2012).

The feeling of empathy enable us to understand other people emotions, desires, and pain on social, behavioral, emotional and cognitive level (Goubert et al., 2005). Recent researchers have found that empathy in health professional is best indicator of establishing better relation between patient and doctor. Similarly the empathic feelings also help to develop feeling of satisfaction in the patients for the medical professional person which ultimately effect the overall health of the person. This effect has been explored in nurse's students. The results of the study indicated that nursing students showed better features of empathy as compare to medical professional. Gender analysis highlighted that female students were found to be higher on empathy as male nursing students. Showing that students professional choice is always best indicator of empathic feelings (Petrucci, La Cerra, Aloisio, Montanari, \& Lancia, 2016). As feeling of empathy help to develop basic features of caring felling for other individual in need (Yu \& Kirk, 2009). For that those involved in help care and medical professions need to care for, understanding the needs of patients, and situational needs of the patients (Zeighami et al., 2012).

Another study also highlighted the link between burnout and empathy among nurses. As like other professional medical person nurses particularly need emphatic feelings for the patients in burn out condition due to work overload, lack of facilities, and emotional intense stimuli is better handled with more empathy. As if one lack empathy for the patients it can lead to compassion fatigue and burnout. Findings of the study showed empathic concern were positively associated with compassion satisfaction and compassion fatigue. Improving the social skills and empathic feelings help to minimize fatigue, burnout, and enhance self-compassion (Duarte, Pinto-Gouveia, \& Cruz, 2016).

However, being over empathic is also dangerous (Hodges \& Biswas-Diener, 2007).As previous literature suggested that being overly sensitive medical professional for patients in pain and suffering can lead to feelings of harmful effects, e.g., burnout or compassion fatigue (Figley, 2012). The implication of empathy has been studied with emotions in the sample of the fieldworkers Ali (2012). Different research 
findings have shown implication of empathy in different educational field including anthropology as empathy help people understanding people emotions and meaning of the individual they are studying. Ali (2012) argued understanding people and thinking of them as insider in spite outsider, helps the people develop happiness for their fieldwork (Ali, 2012). Researches have also shown that empathy feelings fluctuate with time as empathy is not permanent like traits as individual intervention help to improve one's empathic feelings capacity (Hojat, Louis, Maio, \& Gonnella, 2013; Hojat, 2007).

One's humorous manner of problem dealing help individual better adaptation in life stressors. Individual humor styles have diverse effects in different situations as individual bad humor style leads too poor relations. Both male and female have different styles of humor. As male prefer to use more of unfriendly humour, aggressive and selfenhancing humour, whereas females are higher on empathy for that females use more perspective-taking and empathic concern which are positively linked with positive humour styles and negatively linked to negative humour styles. Research also found that empathy act as mediator between humor styles and gender as one's ability to perceive the others feeling and empathetic feelings act as ability to utilize the different humour styles (Wu, Lin, \& Chen, 2016).

Empathic ability in fundamental for successful social-cognitive behavior. Majority of pro-social behaviors are facilitated by in different psychiatric and neurological disorders (Lockwood, 2016). Emotion recognition and empathy in stressful situation helps in forming better interaction and help in understanding people's behaviors and feelings. Women's were better in emotional regulation and empathic feelings as compare to males. Whereas, males were better in recognizing negative emotional regulation strategies and were found to be less empathic (Duesenberg et al., 2016). Different variables have been studied with the empathy similarly the effect of empathy have been explored in relation in with the tourism in diverse manners. It is argued that empathy for the tourist play significant role in improving empathy among the tired and foreign tourists in unknown country (Tucker, 2016).

\section{Rationale}

The aim and rational of our research is to successfully find out the presence of empathy in the adults of Pakistan. On the other hand the research will help to explore that whether this type of human emotion is 
much prevalent in males or in females. The importance of our research is to see different aspects and factors involved in the one's feeling of empathy towards others. Empathy is an important feature within all relationships in creating effective and constructive relations (Hall \& Schmid, 2008). The level of empathetic concern in adults of Pakistani population is discussed in the present study: and the comparison of males and females adults i.e., either the empathy level is higher in males or in females. The study also aims the overall ratio of empathetic concern in the adult's population. Further the study has discussed the impact of different variables that is, role taking behavior, fantasy or imaginative thinking and pro-social behavior on the increasing or decreasing level of empathy.

\section{Objectives}

Our group of interest is the adults i.e., age range 20-40 years of Pakistan. The objective of our research is to find out that whether empathy in the adults of Pakistan is increasing or decreasing with time? The research is conducted to see the effects of different variables involved. Furthermore, the purpose of research is to see that whether the culture of Pakistan is supportive for the increased level of empathy in adults or not.

\section{Hypotheses}

1: The adults of age 20-30 show more empathy than adults of age 30-40. 2: Females show more empathy than males.

\section{Sample}

\section{Method}

The sample was selected by using random sampling technique. In total 150 individuals participated in this research study. About 96 were females and 54 were males. This sample was collected from Rawalpindi and Islamabad. The age ranged from 19-40. Only educated individuals were included as the participants of the research. The education level of the sample ranged between intermediate levels to postgraduate. Also working individuals included. 


\section{Instruments}

To rate the empathy level, an empathy scale was used which has five rating points from 0 (does not describe me well) to 4 (describe me well).

\section{Procedure}

The data was collected from different university students the age was above 19 years, the region was Islamabad and Rawalpindi. The questionnaires have the informed consent and items were measuring the empathy in adults. Participants were allowed to fill the scales either in absence or presence of researcher on the basis of their consent. For demographic information a portion was given on the top of the scale sheet. Confidentiality of information was assured.

\section{Results}

Table 1

Alpha Coefficient Reliability of empathy $(N=150)$

\begin{tabular}{lcc}
\hline Scales & No. of items & Alpha Coefficient \\
\hline Empathy & 31 & 0.87 \\
\hline
\end{tabular}

Table 1 indicates the alpha reliability of empathy scale in adults which is 0.87 that shows that the present scales is highly reliable.

Table 2

Mean, Standard Deviation and t-Value on the Basis of Age on Scores of Empathy $(N=150)$

\begin{tabular}{|c|c|c|c|c|c|c|c|c|}
\hline \multirow[b]{2}{*}{ Variable } & \multicolumn{2}{|c|}{$\begin{array}{c}15-25 \\
(\mathrm{n}=81)\end{array}$} & \multicolumn{2}{|c|}{$\begin{array}{c}26-30 \\
(\mathrm{n}=69)\end{array}$} & \multirow[b]{2}{*}{$\mathrm{t}(150)$} & \multirow[b]{2}{*}{$\mathrm{p}$} & $95 \%$ CI & \multirow[b]{2}{*}{ Cohens $\mathrm{c}$} \\
\hline & $\mathrm{M}$ & SD & $\mathrm{M}$ & SD & & & UL $\quad$ LL & \\
\hline Empathy & 93.04 & 93.04 & 94.81 & 15.95 & .63 & .05 & $7.27 \quad 3.72$ & -0.11 \\
\hline
\end{tabular}

Note. ${ }^{*} \mathrm{p}<.05, \mathrm{CI}=$ Confidence Interval; $\mathrm{LL}=$ Lower Limit; $\mathrm{UL}=$ Upper Limit.

Table 2 indicates that mean score of 25-30 years of age were significantly higher on empathy than 15-25. The current findings of mean difference also approve the hypothesized relationship e.g, the 
adults of age 26-30 show more empathy than adults of age 15-25. The Cohen's $d$ value indicates that age has minor effect on empathy.

Table 3

Mean, Standard Deviation and t-Value on Gender Difference on Empathy $(N=150)$

\begin{tabular}{|c|c|c|c|c|c|c|c|c|c|}
\hline \multirow[b]{2}{*}{$\begin{array}{l}\text { Variabl } \\
\mathrm{e}\end{array}$} & \multicolumn{2}{|c|}{$\begin{array}{l}\text { Male } \\
(n=54)\end{array}$} & \multicolumn{2}{|c|}{$\begin{array}{l}\text { Female } \\
(n=96)\end{array}$} & \multirow[b]{2}{*}{$t(198)$} & \multirow[b]{2}{*}{$p$} & \multicolumn{2}{|c|}{$95 \% C I$} & \multirow[b]{2}{*}{$\begin{array}{l}\text { Cohen's } \\
d\end{array}$} \\
\hline & $M$ & $S D$ & $M$ & $S D$ & & & $U L$ & $L L$ & \\
\hline $\begin{array}{c}\text { Empat } \\
\text { hy }\end{array}$ & 90.37 & 18.90 & 95.25 & 13.68 & -1.82 & .07 & -.17 & -.70 & -.29 \\
\hline
\end{tabular}

Note. $\mathrm{cl}=$ Confidence Interval; $11=$ Lower Limit; $\mathrm{ul}=$ Upper Limit

Table 3 indicates that mean score of female were significantly higher on empathy than males. The current findings of mean difference also support the hypothesis that states females show more empathy than males. The Cohen's d value indicates that gender has minor effect on empathy.

\section{Discussion}

The feeling of empathy is a state in which a person develops comprehension about the emotions of other individuals in surroundings. The individual is expected to experience the same affective feelings that other person would have been experiencing (Eisenberg \& Nancy, 1983). Previous researches, have highlighted the concerns regarding empathy and gender difference existing in empathy. Existing gap in literature regarding empathy, the current study attempted to investigate the gender differences existing in indigenous literature regarding empathy among Pakistani adults. The present study was carried out in two phases. In first phase, the psychometric properties of the study were explored and the current study showed that Empathy scale was found to be very reliable scale for measuring empathy in adults. In the second phase, the research hypothesis was analyzed for testing the research hypothesis. The first hypothesis was that young age group show more empathy as compared to older age group is rejected in present study. Different researches have shown that empathy develop and mature as the individual get elder. Researchers have found that brain scan results shows that younger age individual use less brain areas that are involved in the experience of 
empathy as compare to elder counter parts (Blackmore, 2007). The researchers have found that empathy development is strongly linked with social and emotional understanding among the age changes. Such brain parts are not fully developed and that causes younger adults deficient in feeling guilt and empathy toward others. As one mature the brain area located in pre-frontal cortex linked with empathy, higher thinking, and emotional understanding also develop and mature with passage of time. Empathic concerns with the age and gender have found to that females tend to start showing more empathic feelings for life concern from early age as compare to male counterparts (Christov-Moore et al., 2014). As showing empathy for social role for proper social fit is major characteristics of the females, for that females are anticipated to show more empathic social and emotional manners in every situation than males (Chaplin \& Aldao, 2013; Rose \& Rudolph, 2006).

The second hypothesis was female show more empathy as compared to males was accepted. As the western researches have shown that female are more sensitive and have more empathy as compare to males and this stereotype exists in all cultures (Mehrabian \& O' Reilly, 1980). For years, empathy have been observed to be more dominant in female and this concept has been debated in social, psychoanalysis, developmental and feministic field and giving evidence and results behind the development of empathy in adults (Davis, 1980). The feeling of empathy responses are majorly influenced by variables e.g., gender, culture, social environment, individual pattern of communication and learned skills (Alligood \& May, 2000). Other findings have shown that (Hojat et al., 2002; Fields et al., 2011; Magalhães et al., 2011; Hasan et al., 2013; Kataoka et al., 2009; Chen et al., 2007), female are found to be higher on variable of empathy as compare to male students. Other findings have shown that student gender is a significant self-determining influence that help in selecting appropriate empathic field for then women experience more empathy and select nursing field as compare to males (Leppel, 2001).

\section{Limitations and Suggestions}

Every research is carried out with lot of efforts and every aspect is taken under consideration but like every research, each research have flaws and always leave place for further researches to explore the domains that were left in current research. The limitations and recommendation of present study are as follows; The current study only 
focused on one variable. Other variables that play its role in the construct of empathy were not explored. Further researches can explore other interrelated variable that may increase and decrease empathy in adults. The sample of the study was limited due to time shortage and further research can be carried out on larger sample to make the study result more generalized to population. The current study was carried out on only two demographic characteristics. Further research can explore effect of different demographics that play its role in the enhancing and minimizing the empathy in adults.

\section{References}

Ali, N. (2012). Researcher reflexivity in tourism studies research: Dynamical dances with emotions. In I. Ateljevic, N. Morgan,A. Pritchard (Eds.), The critical turn in tourism studies: Creating an academy of hope (pp. 13-26). London and New York: Routledge.

Alicia J. H., \& Stephanine D. P., (2012). The meaning in empathy: Distinguishing conceptual encoding from facial mimicry, trait empathy, and attention to emotion. Cognition and Emotion, 26(1), 119-128.

Alligood, M.R., May, B.A., 2000. A nursing theory of personal system empathy: interpreting a conceptualization of empathy in King's interacting systems. Nurs. Sci. Q. 13 (3), 243-247

Batson, C. D., Sager, K., Garst, E., Kang, M., Rubchinsky, K., \& Dawson, K. (1997). Is empathy-induced helping due to self-other merging? Journal of Personality and Social Psychology, 73, 495509.

Blackemore, S. J., Ouden, H. D., Choudhury, S., \& Frith, C. (2007). Adolescent development of the neural circuitry for thinking about intentions. Retrieved on September 30, 2014, from, http://scan.oxfordjournals.org/cgi/content/abstract/nsm009v1

Bozarth, J. D. (1998). The person-centered approach: A revolutionary paradigm. Ross-On-Wye, England : PCCS Books.

Brunero, S., Lamont, S., \& Coates, M. (2010). A review of empathy education in nursing. Nursing Inquiry, 17 (1), 65-74. doi: http://dx.doi.org/10.1111/j.1440-1800.2009.00482.x

Chaplin, T. M., \& Aldao, A. (2013). Gender differences in emotion expression in children: A meta-analytic review. Psychological Bulletin, 139(4), 735-765. 
Chen, D., Lew, R., Hershman, W., Orlander, J., 2007. A cross-sectional measurement of medical student empathy. J. Gen. Intern. Med. 22 (10), 1434-1438. http://dx.doi. org/10.1007/s11606-007-0298-x

Christov-Moore, L., Simpson, E. A., Coudé, G., Grigaityte, K., Iacoboni, M., \& Ferrari, P. F. (2014). Empathy: Gender effects in brain and behavior. Neuroscience and Biobehavioral Reviews, 46,604-627.

Cialdini, R. B., Brown, S. L., Lewis, B. P., Luce, C., \& Neuberg, S. L. (1997). Reinterpreting the empathy-altruism relationship: When one into one equals oneness. Journal of Personality and Social Psychology, 73, 481-494.

Clark, B. K. (1980). Empathy: A neglected topic in psychological research: American Psychologist: 35(2), 187-190. doi: http://dx.doi.org/10.1037/0003-066X.35.2.187

Coplan, A., (2011). "Understanding Empathy: Its Features and Effects," in Empathy: Philosophical and Psychological Perspectives, A. Coplan and P. Goldie (eds.), Oxford: Oxford University Press, 3 18.

Davis, M. H. (1980). A multidimensional approach to individual difference in empathy. ISAS Catalog of Selected Documents in Psychology, 10, 85-90.

Davis, M., \& Kraus, L. (1997). Personality and Empathic Accuracy in Empathic Accuracy. W. Ickes (ed.), New York/London: Guilford Press.

DePaulo, B. M. (1992). Nonverbal behavior and self-presentation. Psychological Bulletin, 111, 203-243.

Duarte, J., Pinto-Gouveia, J., \& Cruz, B. (2016). Relationships between nurses' empathy, self-compassion and dimensions of professional quality of life: A cross-sectional study. International Journal of $\begin{array}{lllll}\text { Nursing } & \text { Studies, } & 60 & \text { (1), } & 1-11 .\end{array}$ http://dx.doi.org/10.1016/j.ijnurstu.2016.02.015

Duesenberg, M., Weber, J., Schulze, L., Carmen, L., Roepke, S., Hellmann-Regen, J., Otte, C., Schaeuffele, F., \& Wingenfeld, K. (2016). Does Cortisol modulate emotion recognition and empathy? Psycho-neuroendocrinology, 66 (2016) 221-227. doi: http://dx.doi.org/10.1016/j.psyneuen.2016.01.011

Eisenberg, N. (2007). Empathy related and prosocial behavior. Motivation and Emotion, 278, 71-80 
Elliott, R., Bohart, C. Watson, J. C., Greenberg, L. S. (1997). Empathy Reconsidered: New Directions in Psychotherapy. Psychotherapy, 48, 43-9. doi: http://dx.doi.org/10.1037/a0022187

Fields, S.K., Mahan, P., Tillman, P., Harris, J., Maxwell, K., \& Hojat, M. (2011). Measuring empathy in healthcare profession students using the Jefferson Scale of Physician Empathy: health provide-student version. J. Interprof Care, 25 (4), 287-293. doi: http://dx.doi.org/ $10.3109 / 13561820.2011 .566648$

Figley, C.R. (2012). The empathic response in clinical practice: antecedents and consequences. In: Decety, J. (Ed.), Empathy: From Bench to Bedside. MIT Press, Cambridge, pp. 263-273.

Gesn, P. R., \& Ickes, W. (1999). The development of meaning contexts for empathic accuracy: Channel and sequence effects. Journal of Personality and Social Psychology, 77, 746- 761.

Hall, J. A., \& Schmid Mast, M. (2008). Are women always more interpersonally sensitive than men? Impact of content domain and motivation. Personality and Social Psychology Bulletin, 34, 144155.

Halpern, J. (2007). Patient-Physician Conflicts as Therapeutic Opportunities. Journal of General Internal Medicine, 17, 696-700.

Hasan, S., Al-Sharqawi, N., Dashti, F., Abdul Aziz, M., Abdullah, A., Shukkur, M., Bouhaimed, M., \& Thalib, L. (2013). Level of empathy among medical students in Kuwait University, Kuwait. Med.Princ. Pract, 22 (4), 385-389. doi: http://dx.doi.org/10.1159/000348300

Helen, G. M., \& Valkenburg, P. (2016). Do social media foster or curtail adolescents' empathy? A longitudinal study. Computers in Human Behavior, 63, 118-124. doi: http://dx.doi.org/10.1016/j.chb.2016.05.040

Hodges, S.D., Biswas-Diener, R. (2007). Balancing the empathy expense account: strategies for regulating empathic response. In: Farrow, T.F.D., Woodruff, P.W.R. (Eds.), Empathy in Mental Illness. Cambridge University Press, Cambridge, pp. 389-405.

Hodges, S. D., Kiel, K. J., Kramer, A. D. I., Veach, D., \& Villanueva, B. R. (2010). Giving birth to empathy: The effects of similar experience on empathic accuracy, empathic concern, and perceived empathy. Personality and Social Psychology Bulletin, 36, 398-409. 
Hojat, M., Louis, D.Z., Maio, V \& Gonnella, J.S. (2013). Empathy and health care quality. Am. J. Med. Qual, 28 (1), 6-7. doi: http://dx.doi.org/10.1177/1062860612464731

Ickes, W. (2003). Everyday mind reading: Understanding what other people think and feel. Amherst, NY: Prometheus Books.

Kataoka, H.U., Koide, N., Ochi, K., Hojat, M., Gonnella, J.S., (2009). Measurement of empathy among Japanese medical students: psychometrics and source differences by gender and level of medical education. Acad. Med. 84 (9), 1192-1197. http://dx.doi.org/10. 1097/ACM.0b013e3181b180d4

Kazarian, S. S., \& Martin, R. A. (2006). Humor styles, culture-related personality, wellbeing, and family adjustment among Armenians in Lebanon. Humor International Journal of Humor Research, 19(4), 405-423.

Knafo, A., Zahn-waxler, C., \& Robinson, J. L. (2008). The developmental origins of a disposition toward empathy: genetic and environmental contributions. Emotion, 8 , 737- 752. doi: http://dx.doi.org/10.1037/a0014179

Kohut, H. (1959). Introspection, empathy, and psychoanalysis: an examination of the relationship between modes of observation and theory: International Universities Press.

Kohut, H. (1980). Remarks on receiving the William A. Schonfeld Distinguished Service Award. Adolescent Psychiatry, 8, 51-53.

Konrath, S. (2012). The empathy paradox: increasing disconnection in the age of increasing connection. In R. Luppicini (Ed.), Handbook of research on Technoself: Identity in a technological society. IGI Global.

Konrath, S., O’Brien, E., \& Hsing, C. (2011). Changes in dispositional empathy in American college students over time: a meta-analysis. Personality and Social Psychology Review, 15,180- 198. doi: http://dx.doi.org/10.1177/1088868310377395

Lockwood. L. P. (2016). The anatomy of empathy: vicarious experience and disorders of social cognition. Behavioural Brain Research, 4(5), 1-39. http://dx.doi.org/10.1016/j.bbr.2016.05.048

Magalhães, E., Salgueira, A.P., Costa, P., \& Costa, M.J. (2011). Empathy in senior year and first year medical students: a cross-sectional study. BMC Medical Education, 11, 52-59. doi: http://dx. doi.org/10.1186/1472-6920-11-52 
Mayberry, M. L., \& Espelage, D. L. (2007). Associations among empathy, social competence and reactive proactive aggression subtypes. Journal of Youth and Adolescence, 36, 787-798.

Mehrabian, A., \& O' Reilly, E. (1980). Analysis of personality measure in of basic dimensions of temperament. Journal of Personality and Social Psychology, 38, 492-503.

Newcomb, T. M. \& Hartley, E. L., (1947). Group decision and social change: Readings in social psychology. New York: Holt.

Pedersen, A.B. \& Fenton, A. (2007). Emphasizing the ecology in parasite community ecology. Trends in Ecology and Evolution, 22, 133139.

Petrucci, C., La Cerra, C., Aloisio, F., Montanari, P., \& Lancia, L. (2016). Empathy in health professional students: A comparative cross-sectional study. Nurse Education Today, 41, 1-5. doi; http://dx.doi.org/10.1016/j.nedt.2016.03.022

Rogers, C. (1959). A theory of therapy, personality and interpersonal relationships as developed in the client-centered framework. In (ed.) S. Koch, Psychology: A study of a science. Vol. 3: Formulations of the person and the social context. New York: McGraw Hill.

Rogers, R. W. (1975). A protection motivation theory of fear appeals and attitude change. Journal of Psychology, 91, 93-114.

Trepte, S., \& Reinecke, L. (2013). The reciprocal effects of social network site use and the disposition for self-disclosure: a longitudinal study. Computers in Human Behavior, 29,11021112. doi: http://dx.doi.org/10.1016/j.chb.2012.10.002

Tucke, H. (2016). Empathy and tourism: Limits and possibilities. Annals of Tourism Research, 57, 31-43. doi; http://dx.doi.org/10.1016/j.annals.2015.12.001

Twenge, J. (2014). Generation me-revised and updated: Why today's young Americans are more confident, assertive, entitled and more miserable than ever before. New York, NY: Simon \& Schuster.

Wu, C-Lin., Lin, H-Yi., \& Chen, H-Chih (2016). Gender differences in humour styles of young adolescents: Empathy as a mediator. Personality and Individual Differences, 99, 139-143. 